\title{
Epidemiology of pertussis in Italy: Disease trends over the last century
}

M V Gonfiantini (michaela.gonfiantini@gmail.com) ${ }^{1}$, E Carloni ${ }^{1}$, F Gesualdo $^{1}$, E Pandolfi ${ }^{1}$, E Agricola ${ }^{1}$, E Rizzuto $^{2}$, Iannazzo $^{2}$, M L Ciofi Degli Atti ${ }^{1}$, A Villani ${ }^{1}$, A E Tozzi ${ }^{1}$

1. Bambino Gesù Children's Hospital, IRCCS, Rome, Italy

2. Ministry of Health, Rome, Italy

Citation style for this article:

Gonfiantini MV, Carloni E, Gesualdo F, Pandolfi E, Agricola E, Rizzuto E, lannazzo S, Ciofi Degli Atti ML, Villani A, Tozzi AE. Epidemiology of pertussis in Italy: Disease trends over the last century. Euro Surveill. 2014;19(40):pii=20921. Available online: http://www.eurosurveillance.org/ViewArticle.aspx?Articleld=20921

Article submitted on 23 August 2013 / published on 9 October 2014

We reviewed the epidemiology of pertussis in Italy over the last 125 years to identify disease trends and factors that could have influenced these trends. We described mortality rates (1888-2012), case fatality rates (1925-2012), cumulative incidence rates (19252013) and age-specific incidence rates (1974-2013). We compared data from routine surveillance with data from a paediatric sentinel surveillance system to estimate under-notification. Pertussis mortality decreased from 42.5 per 100,000 population in 1890 to no reported pertussis-related death after 2002 . Incidence decreased from 86.3 per 100,000 in 1927 to 1 per 100,000 after 2008 . Vaccine coverage increased from $32.8 \%$ in 1993 to about $96 \%$ after 2006. As for under-notification, mean sentinel/routine surveillance incidence ratio increased with age (from 1.8 in «1 yearolds to 12.9 in 10-14 year-olds). Pertussis mortality decreased before the introduction of immunisation. Incidence has decreased only after the introduction of pertussis vaccine and in particular after the achievement of a high immunisation coverage with acellular vaccines. Routine surveillance does not show an increase in cumulative incidence nor in $\geq 15$ year-olds as reported by other countries. Underrecognition because of atypical presentation and the infrequent use of laboratory tests may be responsible for undernotification, and therefore affect incidence reports and management of immunisation programmes.

\section{Introduction}

Every year Bordetella pertussis infection causes nearly 16 million cases and 195,000 deaths in children worldwide [1]. Although an estimated $95 \%$ of pertussis cases is observed in developing countries, pertussis is a cause of concern in several developed countries, where the disease seems to be resurging despite a high vaccination coverage [2-4]. Recently, large outbreaks of pertussis have been observed in Europe, the United States and Australia [5-7]. A precise estimate of the burden of pertussis is far from being possible due to the interaction of underrecognition, underreporting, and lack of availability of diagnostic facilities [8].
Several authors have reviewed the epidemiology of pertussis over a long period of time to describe the disease trends and to investigate the role of factors that may affect these trends [4,9-11]. These studies have focused on the epidemiology of pertussis since the introduction of the immunisation in the mid-1940s and have investigated factors potentially involved in the resurgence of pertussis, including increased awareness, diagnosis and reporting, changes in vaccine composition or schedule, waning immunity, and evolution of the bacteria.

In Italy, recommendations for pertussis immunisation were released in 1961, when whole cell vaccines became available [12]. Nevertheless, vaccination coverage increased substantially only after the introduction of acellular pertussis vaccines in 1995 and, even further, after 2002, when the vaccine started to be offered free of charge by all Italian regions [13]. Based on routine surveillance data, Italy is currently a low incidence country and outbreaks or incidence peaks have been rarely reported after the achievement of a high immunisation coverage [14].

We reviewed the epidemiology of pertussis in Italy in the last 125 years to explore factors that affected its trend and to estimate the effect of the immunisation on the disease burden.

\section{Methods}

\section{Data sources}

Data on notified pertussis cases were obtained from the Ministry of Health, which collects notifications from the Surveillance System for Infectious Diseases in Italy [14]. The Italian Surveillance system is passive, universal, and mandatory. Notification of infectious diseases relies on physicians and has been regulated by law with acts issued since 1901. For pertussis the only criterion for notification was a clinical diagnosis based on the opinion of the physician examining the patient, until the introduction of the World Health Organization (WHO) case definition in 1999 that 
better defined diagnostic criteria $[13,15]$. Although the European Union case definition of the year 2008 has been approved at European level [16], pertussis notification in Italy continues to rely mainly on a clinical case definition, and laboratory confirmation is not routinely adopted, despite the availability at national level of real time-PCR and serology [17]. Until 1974, surveillance reports included the total number of notified pertussis cases only; after 1974, reported cases were available by age group.

Data on pertussis mortality and on the Italian population demographics for the period 1862-2009 were obtained from the National Institute of Statistics [18].

We also analysed data on pertussis incidence from a sentinel surveillance system for vaccine preventable diseases in children aged $0-14$ years $[19,20]$. This sentinel surveillance system was in place in Italy between 2000 and 2009 , with about $11 \%$ of all Italian primary care paediatricians participating; the range of participation among the Italian regions was between 7 and $16 \%[20]$.

Data on pertussis vaccine coverage in the first 24 months of life were obtained from the Ministry of Health and from surveys on vaccine coverage [21-24].

\section{Data analysis}

We described pertussis epidemiology in Italy in four time windows. Period 1: 1888 to 1945 , covering the late 19th century and nearly first half of the 2oth century, including the two World Wars; period 2: 1946 to 1960, covering the pre-vaccine era after the second World War; period 3: 1961 to 1994 , covering the time when whole cell vaccine became available and coverage was low ( $(33 \%)$; and period 4: 1995 to 2012 , covering the time when acellular vaccine was used and the coverage high ( $(87 \%)$.

We calculated mortality rates per 100,000 population for pertussis in Italy from 1888 to 2012, case fatality rates from 1925 to 2012, and incidence rates per 100,000 population for the entire Italian population from 1925 to 2013 . We also calculated the age specific incidence rates from 1974 to 2013 for the following age groups: 11 year-olds, 1-4 years-old, 5-9 years-old, 10-14 years-old, $\geq 15$ years-old.

Incidence rates by age group ( $\$ 1$ year-olds, 1-4 yearsold, 5-9 years-old, 10-14 years-old) from the paediatric sentinel surveillance system were used for comparison with routine surveillance data. Assuming a higher sensitivity of the sentinel surveillance system we calculated the average ratio between sentinel surveillance and routine notification rates by age group to estimate under-notification.

Since the sentinel surveillance system reported monthly notification data, we also investigated seasonality. We used one-way Analysis Of Variance (ANOVA) test to compare the period means and F-test to assess if differences between means were statistically significant. Moreover, in order to improve the identification of a seasonal pattern, we used spectral analysis. We examined the cyclical structure of the detrended time series in the frequency domain using the periodogram, which represents an estimate of the spectral density computed using the fast Fourier Transform (FFT). By applying the Hodrick-Prescott filter (with $\lambda=14,400$ ) to the monthly time series of pertussis incidence, we removed the trend component and used the detrended data to build a periodogram through the FFT, allowing to switch from the time function to the frequency domain function. We built up a periodogram with the scales frequency on the $x$-axis and the spectral density on the $\mathrm{y}$-axis. Indicating with $\mathrm{T}$ the period and with $\mathrm{N}$ the number of observations, the scaled frequency was calculated as $f=N / T$, and denoting by $\omega$ the angular frequency, the scaled frequency was $f=\omega *(N / 2 \pi)$, where $\omega=2 \pi / T$.

Stata 11 and Gretl 1.9.14 were used for data analysis.

\section{Results}

\section{Demographic changes}

During the last century in Italy birth and mortality rates have progressively declined, whereas life expectancy has increased. Live births decreased from 37.5 per 1,000 inhabitants in 1862 to 9.5 in 2009. This corresponds to a reduction by nearly half from $1,119,563$ alive newborns in 1888 to 566,125 in 2009, with a more marked decline during the World Wars and since the 1970s. Mortality rates for all causes decreased from 27.4 per 1,000 inhabitants in 1888 to 9.8 in 2009. The Italian population has continuously grown from 26 million in 1862 to 60 million in 2009, with a progressive aging of the population. The aging index, i.e. the ratio between adults aged $\geq 65$ years and children aged $\leq 14$ years, has increased from $15.9 \%$ in 1888 to $143.4 \%$ in 2009.

\section{Descriptive Analysis}

\section{Period 1 (1888 to 1945)}

Pertussis mortality progressively decreased from 42.5 per 100,000 population in 1890 to 3.6 in 1945 (Figure 1). Case fatality rate decreased from $13.4 \%$ in 1925 to $6.7 \%$ in 1942, thereafter it increased again during the last two years of the second World War to $10.7 \%$ in 1944 and $10.3 \%$ in 1945 respectively (Figure 1). Pertussis incidence was high between 1925 and 1941, ranging between 50 and 70 per 100,000 population, with a peak of 86.3 in 1927 (Figure 2). The lowest incidence of pertussis was reported in 1944 (23.3/100,000). Epidemic cycles occurred regularly every three to five years.

\section{Period 2 (1946 to 1960, pre-vaccine era)}

Between 1946 and 1960, pertussis mortality and case fatality rates continued to decrease and reached very low numbers (Figure 1). Mortality decreased from 5.5 per 100,000 population in 1946 to 0.2 in 1960, and 
FIGURE 1

Pertussis mortality and case fatality, Italy, 1888-2012 and 1925-2012 respectively

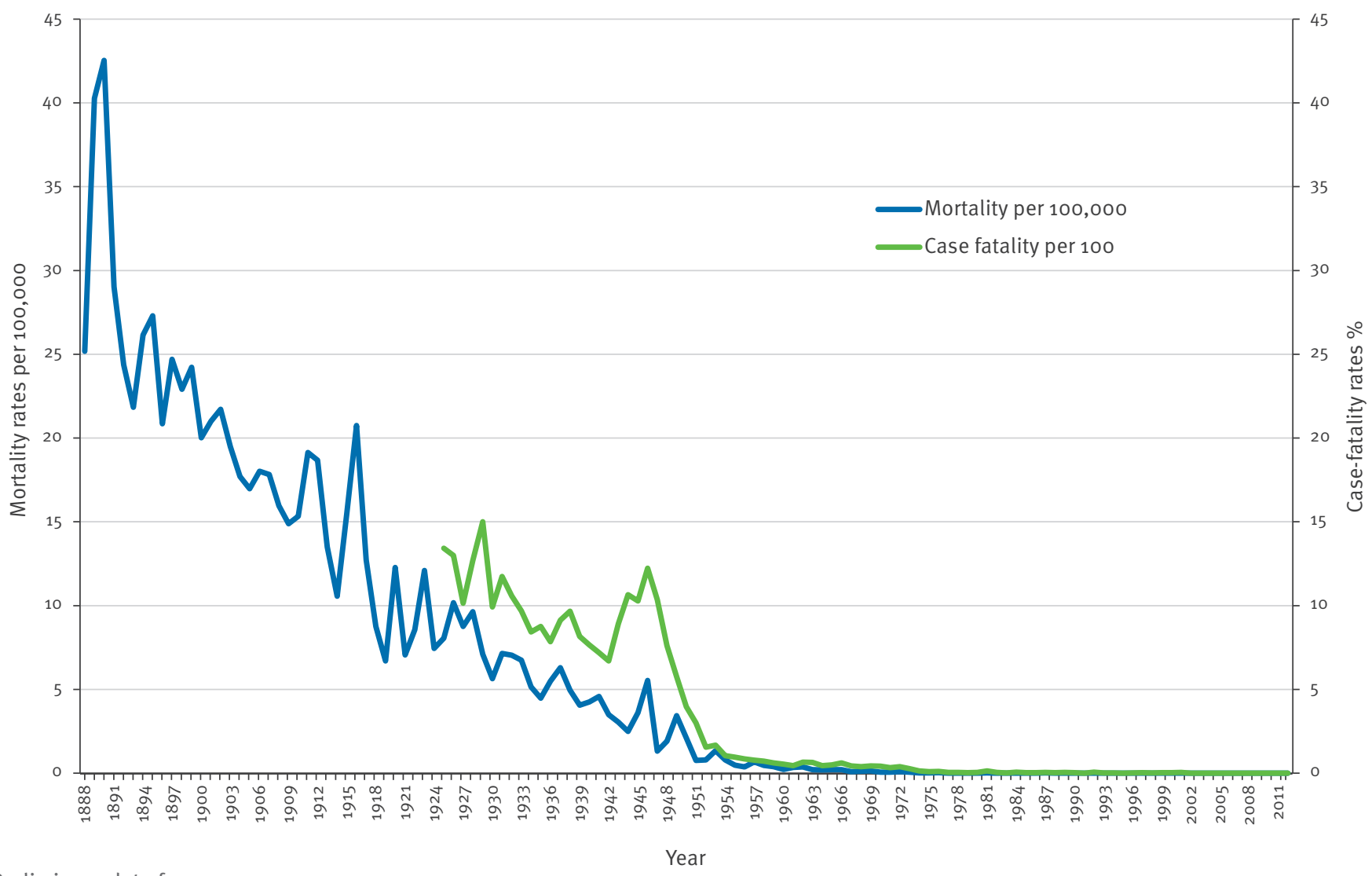

Preliminary data for 2012

FIGURE 2

Pertussis incidence and pertussis immunisation coverage at 24 months, Italy, 1925-2013

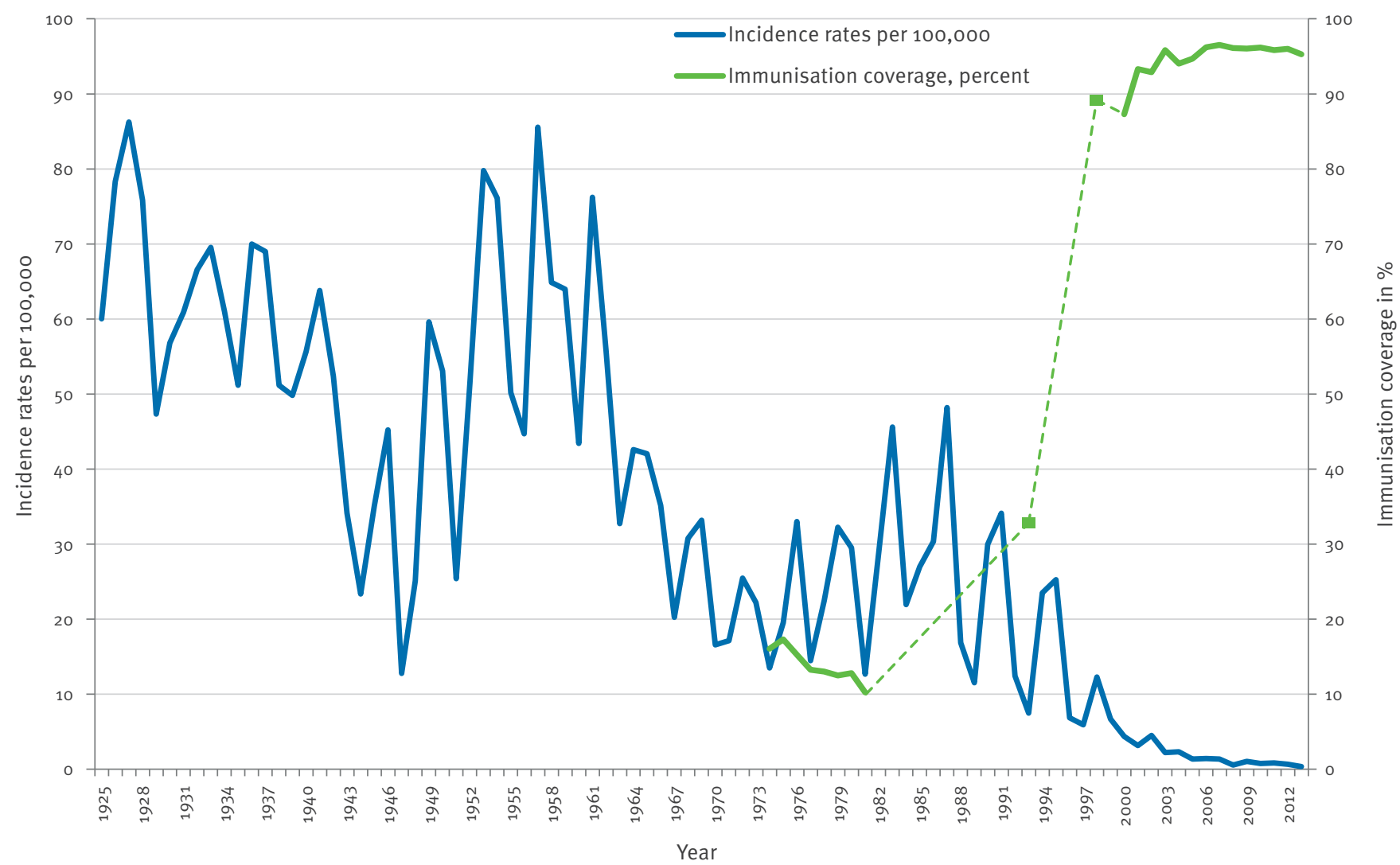

Preliminary data for 2012 and 2013

www.eurosurveillance.org

3

Check for updates 
case fatality rate from $12.2 \%$ to $0.5 \%$. Pertussis deaths decreased from over 2,000 to around 100 per year. At the same time, a high and increasing incidence of pertussis was observed (Figure 2). Pertussis epidemic cycles continued to occur every three to five years with increasing incidence peaks (59.6/100,000 in $1949,79.8 / 100,000$ in 1953). The highest value (85.6/ 100,000) was observed in 1957.

Period 3 (1961 to 1994, whole cell vaccine, low coverage) In 1961, recommendations for pertussis immunisation with the whole cell vaccine were released in Italy. Vaccination was not mandatory and immunisation policies differed among regions, with only some regions offering the immunisation for free [12]. Hereafter, pertussis mortality decreased further from 0.34 per 100,000 population in 1961 to 0.00 in 1994 (Figure 1). Mortality decreased from over 100 pertussis-related deaths per year between 1961 and 1966, to two pertussis-related deaths in 1994 . The case fatality rate was below $1 \%$ during the whole period, with values between 0.1 and $0.0 \%$ after 1982 (Figure 1).

With the introduction of the whole cell vaccine, pertussis incidence showed a decreasing trend from 76.2 per 100,000 population in 1961 to 12.7 in 1981, although immunisation coverage was very low, with reported figures ranging between 10 and $16 \%$ during the years 1974 to 1981 (Figure 2). Epidemic cycles continued to occur every three to five years. An incidence peak was observed in the period 1983 to 1987 , reaching values of 45.6 per 100,000 population in 1983 and 48.2 in 1987. Afterwards, incidence decreased again and the lowest value was reached in 1993 (7.5/100,000), when a vaccine coverage of $32.8 \%$ was reached. From 1974 to 1994 pertussis incidence was highest in children «1 year of age (range: 108.7-618.6/100,000 population) and in 1-4 years-old (range: 93.6-639.9/100,000)

\section{FIGURE 3}

Age percent distribution of pertussis cases, Italy, 1974-2013

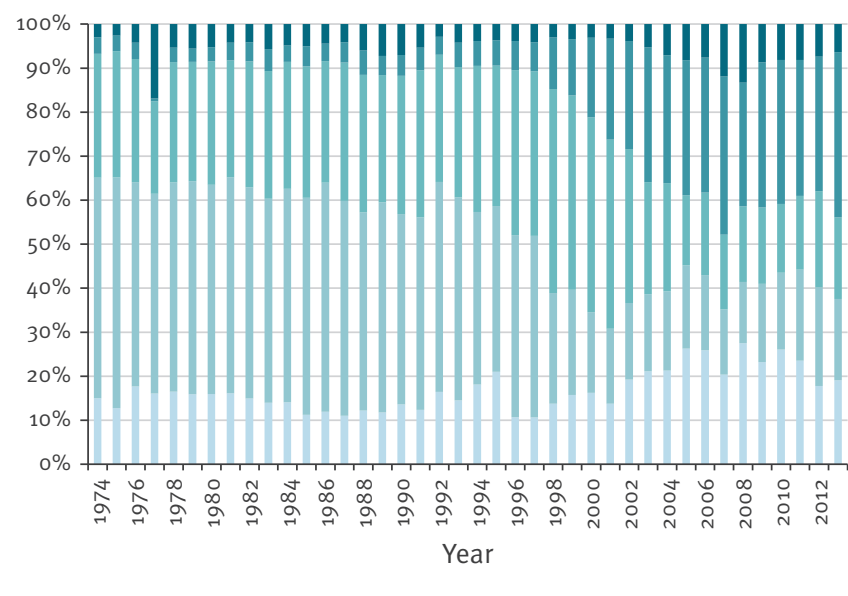

<1 year $\quad 1-4$ years $\quad 5-9$ years $\quad 10-14$ years $\geq 15$ years

Preliminary data for 2012 and 2013
(Figure 3 ). Incidence in 5-9 year-old children was intermediate (range: 40.5-294.2/100,000 population), whereas pertussis incidence was lowest in adolescents (range: $1.2-34.4 / 100,000$ population) and adults (range: $0.4-3.4 / 100,000$ ).

Period 4 (1995 to 2013, acellular vaccine, high coverage) In 1995, acellular pertussis vaccines replaced whole cell vaccines with a recommended two-dose primary series and a booster at the age of 11 months. An additional preschool booster was recommended in 1999, and a booster in adolescents introduced in the childhood immunisation programme in 2012 [25]. Vaccine coverage increased dramatically, with an uptake of $89.2 \%$ in $1998,87.3 \%$ in $2000,94.7 \%$ in 2005 , and $96.2 \%$ in 2010 (Figure 2). From 1995 to 2001, only one pertussis death per year was reported. No deaths have been reported since 2002 .

After the introduction of the acellular pertussis vaccine, incidence peak values have decreased from 25.3 per 100,000 population in 1995 to 12.3 in 1998 (Figure 2). Since 1999, incidence has been below seven. Rates decreased below three per 100,000 population after the vaccine was offered free of charge in all Italian regions in 2002 and to around one per 100,000 population since 2008. Since 2002, epidemic cycles have been less clearly identifiable, due to the low incidence of pertussis. After the introduction of the acellular vaccines, incidence decreased in all age groups (Figure 3). Children « 1 year of age continued to be the age group with the highest incidence rates (range: 6.9556.4/100,000 population). Between 1998 and 2004, incidence rates were higher among children aged 5-9 years (range: 12.1-116.4/100,000 population) than in children aged 1-4 years (range: 10.5-81.8/100,000). Since 2003 , incidence rates in 10-14 year-olds (range: 2.5-13.6/100,000 population) exceed rates in 1-4 (range: $1.6-11.2 / 100,000)$ and 5-9 years-old children (range: $1.3-12.4 / 100,000$ ). The $\geq 15$ years-old population, remains the age group with the lowest incidence rates (range: 0.0-1.1/100,000 population). After the introduction of the acellular vaccines, proportional distribution of reported cases by age group has changed (Figure 3). The proportion of reported cases in 1-4 and 5-9 year-olds has decreased, whereas the proportion of reported cases in those «1 year of age and 10-14 years-old has increased. Only a slight increase in the proportion of reported cases in the group $\geq 15$ years of age has been observed.

\section{Seasonality}

Monthly data from the paediatric sentinel surveillance system from 2000 to 2009 showed a significant seasonal difference in incidence. The lowest incidence was reported in the fourth quarter, with a mean of 5.9 per 100,000 population, whereas values between 10 and 12.7 were observed during the other quarters $(p$-value $=0.0027)$. The periodogram shows a peak for $\mathrm{f}=10$ (corresponding to a periodicity of 11.8 months), with a spectral density of 61.04 and $\omega=0.53$ (Figure 4). 
An additional peak of lower amplitude (spectral density $=22.44$ ) is shown for $\mathrm{f}=5$ (corresponding to $a$

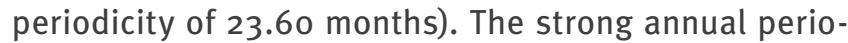
dicity in the Italian pertussis incidence peaked between March and August (spring/summer), while the minimum incidence was observed between September and February (autumn/winter). The annual and the biannual components of the time series stand for a sustained circulation of the disease in the period included in the analysis.

\section{Under-notification}

Data from the paediatric sentinel surveillance system in the period 2001 to 2008 showed significantly higher incidence rates than the routine surveillance, ranging from 13 to 360 per 100,000 population depending on the age group (Figure 5). Incidence rates showed a decreasing trend in all age groups. The age group with the highest incidence rates was 10-14 year-olds. Since 2005 , incidence rates in 1-4 year-olds have exceeded incidence in children « 1 year of age and those 5-9 years-old. Under-notification was lowest in children «1 year of age, with a mean sentinel/routine surveillance ratio of 1.8 in this age group. Under-notification increased in older age groups, with a mean ratio of 11.8 in 1-4 years-old children, 9.2 in 5-9 year-olds, and 12.9 in 10-14 year-olds.

\section{Discussion}

The epidemiology of pertussis has dramatically changed in Italy over the last century. Pertussis mortality has greatly declined, with no reported pertussisrelated deaths since 2002 . Pertussis incidence has decreased after the introduction of immunisation, in particular after achieving a high immunisation coverage with acellular vaccines after the year 2000. No resurgence of pertussis has been detected by routine surveillance data as of yet.

The improved living conditions of the Italian population and the achievement of better healthcare after the two World Wars likely affected pertussis mortality. Mortality and case fatality rates decreased indeed dramatically to values below 1 per 100,000 population and below $1 \%$ respectively, before the introduction of pertussis immunisation in the 1960 .

\section{FIGURE 5}

Pertussis incidence in children $0-14$ years-old, Italian paediatric sentinel surveillance system , 2001-2008

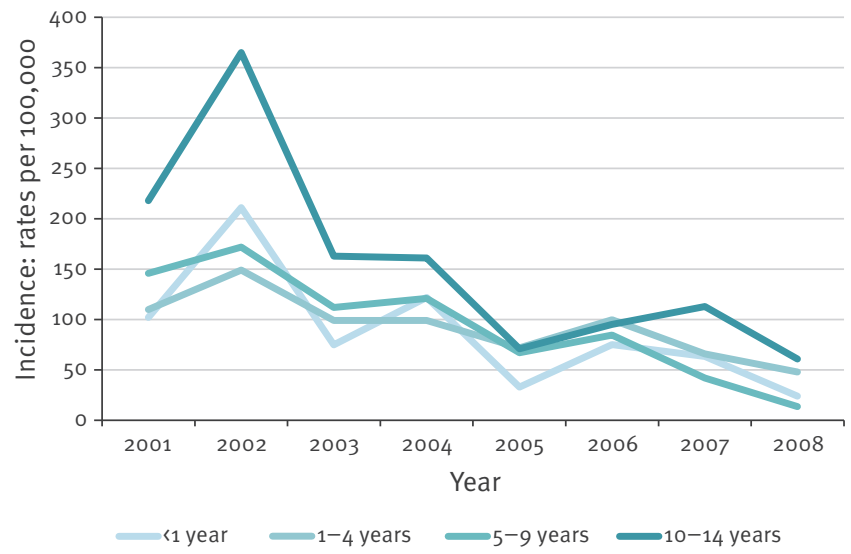

\section{FIGURE 4}

Periodogram of pertussis incidence in children 0-14 years-old, Italian paediatric sentinel surveillance system, January 2000October 2009

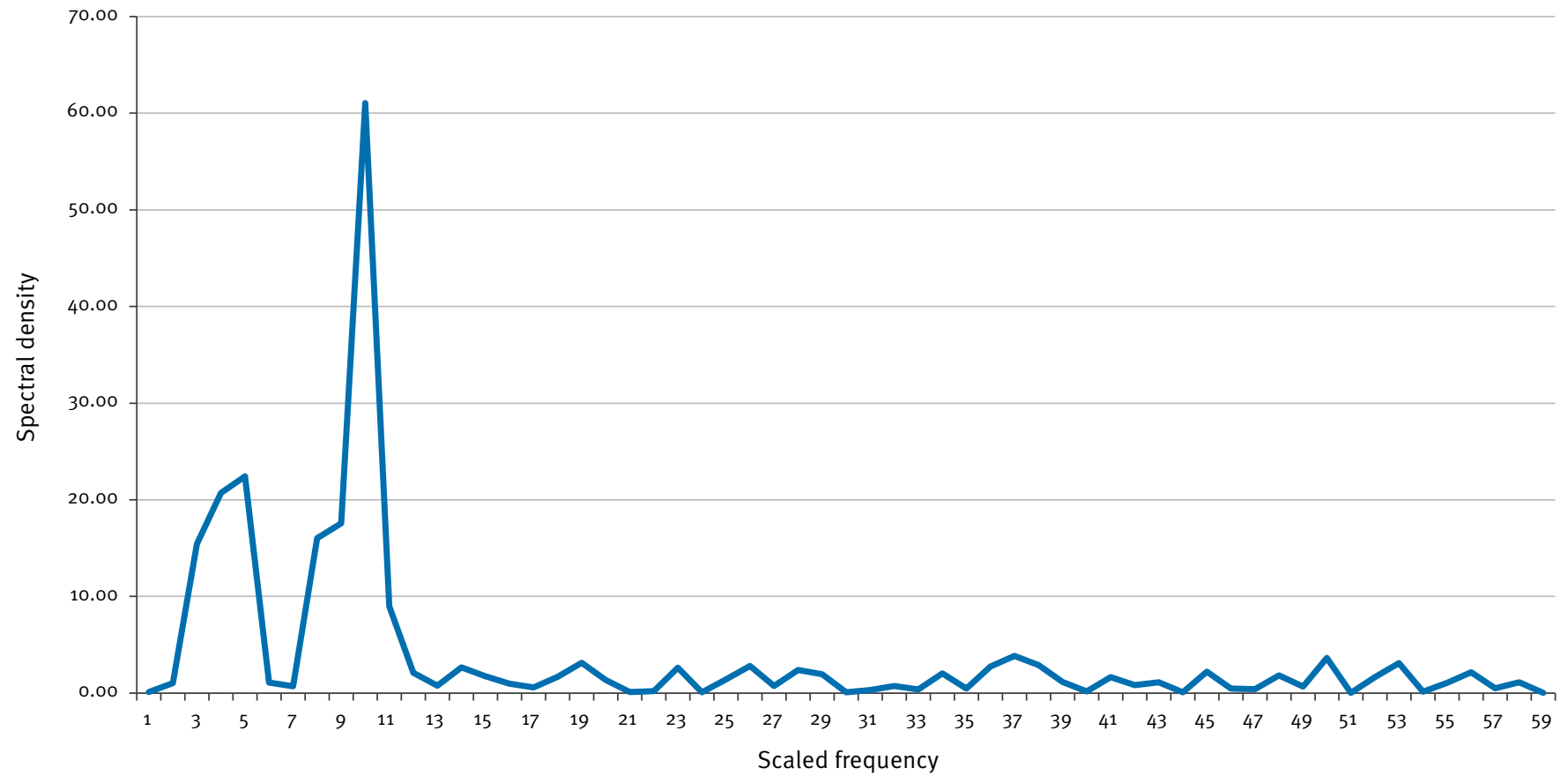


The introduction of pertussis immunisation has markedly influenced the incidence of the disease. Pertussis incidence started decreasing after the introduction of the whole cell vaccine in 1961, even if vaccine coverage was low. The most evident decrease in pertussis incidence has been observed after 1995, when the acellular pertussis vaccine was introduced, allowing to reach values $<5$ per 100,000 population after the year 2000. Since 2002, the vaccine has been offered free of charge to children 11 year of age by all Italian regions, allowing to achieve an immunisation coverage of about $96 \%$ after 2006.

The introduction of acellular vaccines and the progressive increase in vaccine coverage have also influenced the age distribution of the disease over the last two decades. During the low-coverage period, the highest pertussis incidence was in children $<1$ year and in those 1-4 years of age. After 1995, the highest incidence rates persisted in children 11 year of age, while incidence in 1-4 year-olds, the ones more protected by the infant immunisation, started decreasing. After an initial increase, incidence in children $5-9$ years-old has been decreasing since 2003, following the introduction of the preschool booster in 1999. The constant increase of pertussis incidence in 10-14 years-old children can be explained by waning immunity [26-30], or by an increase in awareness of pertussis in this age group [11].

The introduction of immunisation programmes decreases the accumulation of susceptible individuals and therefore delays the occurrence of epidemic cycles [31]. In the case of pertussis in Italy, we observed that regular epidemic cycles persisted despite the demographic changes and even after the introduction of the immunisation. Only once a high immunisation coverage of $>94 \%$ was reached after 2002 , epidemic cycles became unapparent. Immunity starts to wane between four to 10 years after pertussis immunisation, or even earlier according to recent reports [28-30], and also the protection after the natural disease is not lifelong $[26,27]$. Therefore, susceptible individuals are likely to have accumulated over time, especially in older age groups. Nevertheless, according to data from the routine surveillance system, Italy is not experiencing a resurgence of pertussis as reported in other developed countries [2-7]. In these countries a resurgence started to be observed several years after reaching high vaccine uptake rates $[4,32]$. Considering that in Italy a high immunisation coverage has been reached only after the year 2002, a resurgence of pertussis may be seen only in the years to come.

Data from the routine surveillance system do not show an increase in pertussis incidence in the $\geq 15$ yearsold population in Italy, as described in other European countries [2]. This is in contrast with a recent Italian seroepidemiological study, which suggests that $B$. pertussis actually circulates among adolescents and adults [33]. Underrecognition and missed diagnosis may partially explain the very low incidence rates reported in this age group in Italy. Symptoms of pertussis in adolescents, adults and previously vaccinated individuals are not always as typical as in younger children $[34,35]$. Indeed, a recent study showed that Italian physicians seldom suspect pertussis, and therefore do not request a laboratory confirmation test in older patients with a chronic cough [36]. The scarce use of laboratory confirmation of a suspected $B$. pertussis infection obviously reduces the possibility of diagnosis in patients with atypical pertussis presentation in all age groups.

Under-notification may also affect surveillance reports. Our results show a high under-notification ratio when comparing incidence figures from a sentinel surveillance system with routine reports. Moreover, under-notification ratios increased with age. Similar results have been recently reported from Poland [37]. Assuming that incidence figures based on surveillance reports should be adjusted for underrecognition and under-notification, the real incidence of pertussis may be much higher compared to figures reported through routine surveillance, with a higher difference in older age groups.

While in other countries changes in diagnostic criteria and techniques may have affected the reported pertussis incidence, notification in Italy still mainly relies on a clinical diagnosis, although laboratory diagnosis of $B$. pertussis infection is available [17]. This is obviously a limitation for the reliability of the surveillance system, but allows comparison of data over a very long time period.

In conclusion, before immunisation was available, pertussis incidence had not been influenced by historical or demographic changes in Italy, whereas mortality due to pertussis had already dramatically decreased. An evident decrease in pertussis incidence in Italy occurred after the introduction of immunisation and in particular after the achievement of a high vaccine coverage with the acellular vaccine. However, a decreased awareness of the disease, with underrecognition and under-notification, may play a role that has to be taken into account for the development, implementation and evaluation of immunisation programmes. Management of immunisation programmes strongly relies on surveillance data. Quality and sensitivity of surveillance should constantly be monitored and reviewed to adjust reported incidence rates. Since based on experiences elsewhere, a pertussis resurgence may occur in Italy, physicians should be educated to take into account a diagnosis of pertussis in individuals with atypical presentation and in older age groups. Moreover, the use of available laboratory confirmation methods, especially $P C R$, should be strongly supported in order to improve surveillance. The extent of underrecognition and under-notification should be thoroughly investigated to identify the real burden of pertussis in Italy. 


\section{Conflict of interest}

A E Tozzi received grants for clinical studies by Wyeth/Pfizer (conjugate pneumococcal vaccine), Glaxo SmithKline (measles mumps rubella varicella vaccine) and Sanofi Pasteur MSD (hexavalent vaccine).

\section{Authors' contributions}

Michaela V.Gonfiantini: designed the study, coordinated and carried out data collection and data analysis, drafted the initial manuscript, and approved the final manuscript as submitted.

Emanuela Carloni: carried out data analysis, drafted the initial manuscript, and approved the final manuscript as submitted.

Francesco Gesualdo: collaborated in data analysis, revised the manuscript, and approved the final manuscript as submitted.

Elisabetta Pandolfi: collaborated in data analysis, critically reviewed the manuscript, and approved the final manuscript as submitted.

Eleonora Agricola: collaborated in data analysis, critically reviewed the manuscript, and approved the final manuscript as submitted.

Elvira Rizzuto: provided data and analysis on the epidemiology of pertussis in Italy based on routine surveillance, critically reviewed the manuscript, and approved the final manuscript as submitted.

Stefania lannazzo: provided data and analysis on the epidemiology of pertussis in Italy based on routine surveillance, critically reviewed the manuscript, and approved the final manuscript as submitted.

Marta L. Ciofi degli Atti: carried out data collection and analysis on the paediatric sentinel surveillance system, critically reviewed the manuscript, and approved the final manuscript as submitted.

Alberto Villani: reviewed and revised the manuscript, and approved the final manuscript as submitted.

Alberto E. Tozzi: conceptualised and designed the study, coordinated and supervised data analysis, drafted the initial manuscript, and approved the final manuscript as submitted.

\section{References}

1. Black RE, Cousens S, Johnson HL, Lawn JE, Rudan I, Bassani DG, et al. Global, regional, and national causes of child mortality in 2008: A systematic analysis. Lancet. 2010;375(9730):1969-87. http://dx.doi.org/10.1016/ S0140-6736(10)60549-1

2. Celentano LP, Massari M, Paramatti D, Salmaso S, Tozzi AE, EUVAC-NET Group. Resurgence of pertussis in Europe. Pediatr Infect Dis J. 2005;24(9):761-5. http://dx.doi.org/10.1097/01. inf.0000177282.53500.77

3. Tanaka M, Vitek CR, Pascual FB, Bisgard KM, Tate JE, Murphy TV. Trends in pertussis among infants in the United States, 1980-1999. JAMA. 2003;290(22): 2968-75. http://dx.doi. org/10.1001/jama.290.22.2968

4. Rohani P, Drake JM. The decline and resurgence of pertussis in the US. Epidemics. 2011;3(3-4):183-8. http://dx.doi. org/10.1016/j.epidem.2011.10.001

5. Health Protection report. Confirmed pertussis in England and Wales: data to end-November 2012. London, United Kingdom, 6(51); 21 Dec 2012. Available from: http://webarchive. nationalarchives.gov.uk/20140505162355/http://www.hpa.org. uk/hpr/archives/2012/news5112.htm\#prtsss1211

6. Centers for Disease Control and Prevention (CDC). Pertussis epidemic - Washington, 2012. MMWR Morb Mortal Wkly Rep. 2012;61(28):517-22

7. Rosewell A, Spokes PJ, Gilmour RE. NSW Annual vaccinepreventable disease report, 2011. NSW Public Health Bull. 2012;23(9-10):171-8. http://dx.doi.org/10.1071/NB12086

8. World Health Organization (WHO). Generic protocol for estimating the burden of Pertussis in young children. Geneva: WHO; 2005. Available from: http://www.who.int/immunization/ documents/WHO_IVB_05.15/en/.
9. Clark TA, Messonnier NE, Hadler SC. Pertussis control: time for something new? Trends Microbiol. 2012;20(5):211-3. http:// dx.doi.org/10.1016/j.tim.2012.03.003

10. Hellenbrand W, Beier D, Jensen E, Littmann M, Meyer C, Oppermann $\mathrm{H}$, et al. The epidemiology of pertussis in Germany: past and present. BMC Infect Dis. 2009;9:22. http:// dx.doi.org/10.1186/1471-2334-9-22

11. Jackson DW, Rohani P. Perplexities of pertussis: recent global epidemiological trends and their potential causes. Epidemiol Infect. 2014:142(4):672-84. http://dx.doi.org/10.1017/ So950268812003093

12. Binkin NJ, Salmaso S, Tozzi AE, Scuderi G, Greco D, Greco D. Epidemiology of pertussis in a developed country with low vaccination coverage: the Italian experience. Pediatr Infect Dis J. 1992;11(8): 653-61.

13. Rota MC, D’Ancona F, Massari M, Mandolini D, Giammanco $A$, Carbonari $\mathrm{P}$, et al. How increased pertussis vaccination coverage is changing the epidemiology of pertussis in Italy. Vaccine. 2005;23(46-47): 5299-305. http://dx.doi. org/10.1016/j.vaccine.2005.07.061

14. Ministero della Salute. [Italian Ministry of Health]. Bollettino epidemiologico. [Epidemiological bulletin]. Rome: Ministero della Salute; 2014. Italian. Available from: http://www.salute. gov.it/portale/temi/p2_6.jsp?lingua=italiano\&id=812\&area $=M$ alattie \%2oinfettive \&menu=vuoto

15. World Health Organization (WHO). WHO - recommended standards for surveillance of selected vaccine-preventable diseases. Feb 2003. Geneva: WHO; 2003. Available from: http://apps.who.int/iris/bitstream/10665/68334/1/ WHO_V-B_03.01_eng.pdf?ua=1

16. European Commission. Commission implementing decision of 8 August 2012 amending Decision 2002/253/EC laying down case definitions for reporting communicable diseases to the Community network under Decision No 2119/98/EC of the European Parliament and of the Council. Pertussis case definition. Official Journal of the European Union. Luxembourg: Publications Office of the European Union. 27.09.2012:L 262/22. Available from: http://eur-lex.europa.eu/LexUriServ/ LexUriServ.do?uri=0J:L:2012:262:0001:0057:EN:PDF\#page $=22$

17. European Centre for Disease Prevention and Control (ECDC). Annual Epidemiological Report on Communicable Diseases in Europe 2009. Pertussis. June 2014, revised version. Stockholm: ECDC; 2010. Available from: http://ecdc.europa. eu/en/publications/Publications/0910_SUR_Annual Epidemiological_Report_on_Communicable_Diseases_in Europe.pdf\#page $=191$

18. L'archivio della statistica Italiana. Serie Storiche. [Italian National Institut of Statistics time series]. [Accessed 15 Sep 2014]. Italian.Available from: http://seriestoriche.istat.it/ index.php?id=6\&user_10oind_pi1[uid_categoria] $=2 \& \mathrm{cHash}=6$ b3a0817232de37d9aa509c692bo89b4

19. Ciofi Degli Atti ML, Salmaso S, Bella A, Arigliani R, Gangemi M, Chiamenti G, et al. Pediatric sentinel surveillance of vaccine-preventable diseases in Italy. Pediatr Infect Dis J. 2002;21(8):763-8. http://dx.doi. org/10.1097/00006454-200208000-00013

20. Sorverglianza Pediatri Sentinella (SPES). Sentinel surveillance system for vaccine preventable infectious diseases in the pediatric age. Italian. [Accessed 15 Sep 2014]. Available from: http://www.spes.iss.it/.

21. Ministero della Salute [Italian Ministry of Health]. Vaccinazioni dell'età pediatrica, in Italia: coperture vaccinali. [Pedriatric vaccination in Italy: vaccine coverage]. 29 Jul 2014. Rome: Ministero della Salute; 2014. Italian. Available from: http:// www.salute.gov.it/imgs/C_17_pagineAree_811_listaFile_ itemName_11_file.pdf

22. Salmaso S, Stazi MA, Luzi S, Greco D. Immunization coverage in Italy. Bull World Health Organ. 1987;65(6):841-6.

23. Childhood vaccination coverage in Italy: results of a sevenregion survey. The Italian Vaccine Coverage Survey Working Group. Bull World Health Organ. 1994;72(6):885-95.

24. Salmaso S, Rota MC, Ciofi Degli Atti ML, Tozzi AE, Kreidl $P$. Infant immunization coverage in Italy: Estimates by simultaneous EPI cluster surveys of regions. ICONA Study Group. Bull World Health Organ. 1999;77(10):843-51.

25. Ministero della Salute. [Italian Ministry of Health]. Piano nazionale prevenzione vaccinale (PNPV) 2012-2014. [National immunisation programme 2012-2014]. Rome: Ministero della Salute; 2012. Italian. Available from: http://www.salute.gov.it/ imgs/C_17_pubblicazioni_1721_allegato.pdf.

26. Wendelboe AM, Van Rie A, Salmaso S, Englund JA. Duration of immunity against pertussis after natural infection or vaccination. Pediatr Infect Dis J. 2005;24(5 Suppl):S58-61. http://dx.doi.org/10.1097/01.inf.0000160914.59160.41

27. Wearing HJ, Rohani P. Estimating the duration of pertussis immunity using epidemiological signatures. PLoS Pathog. 
2009;5(10):e1000647. http://dx.doi.org/10.1371/journal. ppat.1000647

28. Klein NP, Bartlett J, Rowhani-Rahbar A, Fireman B, Baxter R. Waning protection after fifth dose of acellular pertussis vaccine in children. N Engl J Med. 2012;367(11):1012-9. http:// dx.doi.org/10.1056/NEJMoa1200850

29. Misegades LK, Winter K, Harriman K, Talarico J, Messonnier NE, Clark TA, et al. Association of childhood pertussis with receipt of 5 doses of pertussis vaccine by time since last vaccine dose, California, 2010. JAMA. 2012;308(20):2126-32. http://dx.doi. org/10.1001/jama.2012.14939

30. Witt MA, Katz PH, Witt DJ. Unexpectedly limited durability of immunity following acellular pertussis vaccination in preadolescents in a North American outbreak. Clin Infect Dis. 2012;54(12):1730-5. http://dx.doi.org/10.1093/cid/cis287

31. Fine P, Eames K, Heymann DL. "Herd immunity": a rough guide. Clin Infect Dis. 2011;52(7):911-6. http://dx.doi.org/10.1093/cid/ ciroo7

32. Amirthalingam G, Gupta S, Campbell H. Pertussis immunisation and control in England and Wales, 1957 to 2012: a historical review. Euro Surveill. 2013;18(38):pii=20587

33. Gabutti G, Bergamini M, Bonanni P, Guido M, Fenoglio D, Giammanco A, et al. Assessment of humoral and cell-mediated immunity against bordetella pertussis in adolescent, adult, and senior subjects in Italy. Epidemiol Infect. 2008;136(11):1576-84. http://dx.doi.org/10.1017/ So950268807000192

34. Ward JI, Cherry JD, Chang SJ, Partridge S, Keitel W, Edwards $\mathrm{K}$, et al. Bordetella pertussis infections in vaccinated and unvaccinated adolescents and adults, as assessed in a national prospective randomized acellular pertussis vaccine trial (APERT). Clin Infect Dis. 2006;43(2):151-7. http://dx.doi. org/10.1086/504803

35. Tozzi AE, Rava L, Ciofi degli Atti ML, Salmaso S, Progetto Pertosse Working Group. Clinical presentation of pertussis in unvaccinated and vaccinated children in the first six years of life. Pediatrics. 2003;112(5):1069-75. http://dx.doi. org/10.1542/peds.112.5.1069

36. Gonfiantini MV, Villani A, Gesualdo F, Pandolfi E, Agricola E, Bozzola E, et al. Attitude of Italian physicians toward pertussis diagnosis. Hum Vaccin Immunother. 2013;9(7)1485-8. http:// dx.doi.org/10.4161/hv.24734

37. Stefanoff P, Paradowska-Stankiewicz IA, Lipke M, Karasek $E$, Rastawicki W, Zasada A et al. Incidence of pertussis in patients of general practitioners in Poland. Epidemiol Infect. 2014;142(4):714-23. http://dx.doi.org/10.1017/

So950268813001684 